\title{
Is type 2 diabetes an adiposity-based metabolic disease? From the origin of insulin resistance to the concept of dysfunctional adipose tissue
}

\author{
Paolo Sbraccia ${ }^{1,2}$ - Monica D'Adamo ${ }^{1,2} \cdot$ Valeria Guglielmi ${ }^{1,2}$
}

Received: 4 January 2021 / Accepted: 12 January 2021 / Published online: 8 February 2021

(c) The Author(s) 2021

\begin{abstract}
In the last decades of the past century, a remarkable amount of research efforts, money and hopes was generated to unveil the basis of insulin resistance that was believed to be the primary etiological factor in the development of type 2 diabetes. From the Reaven's insulin resistance syndrome to the DeFronzo's triumvirate (skeletal muscle, liver and beta-cell) and to Kahn's discovery (among many others) of insulin receptor downregulation and autophosphorylation, an enthusiastic age of metabolic in vivo and in vitro research took place, making the promise of a resolutory ending. However, from many published data (those of insulin receptoropathies and lipodystrophies, the genome-wide association studies results, the data on reversibility of type 2 diabetes after bariatric surgery or very-low-calorie diets, and many others) it appears that insulin resistance is not a primary defect but it develops secondarily to increased fat mass. In particular, it develops from a mismatch between the surplus caloric intake and the storage capacity of adipose tissue. On this basis, we propose to change the today's definition of type 2 diabetes in adiposity-based diabetes.

Level of Evidence as a narrative review a vast array of studies have been included in the analysis, ranging from properly designed randomized controlled trials to case studies; however, the overall conclusion may be regarded as level IV.
\end{abstract}

Keywords Type 2 diabetes · Obesity · Insulin resistance $\cdot$ Fat mass $\cdot$ Adipose tissue

\section{Introduction}

No area in endocrinology and few areas in all biomedicine research fields have had such an extraordinary scientific explosion as insulin resistance. From the few initial reports of diabetic patients requiring very high doses of insulin [1, 2], the real cornerstone was the development of radioimmunoassay (RIA) of peptide hormones by Solomon Berson and Rosalyn Yalow [3]. For this great advancement, that marked the modern era of hormone research, R. Yalow was awarded the Nobel Prize in Physiology or Medicine in 1977. Consequently, for the first time, it was proven that in type 2 diabetes insulin was inefficient rather than deficient [4].

Paolo Sbraccia

sbraccia@med.uniroma2.it

1 Dipartimento di Medicina dei Sistemi, Università di Roma "Tor Vergata", Via Montpellier, 1, 00133 Rome, Italy

2 Unit of Internal Medicine, Obesity Center, Policlinico Tor Vergata, Rome, Italy
This change in paradigm, at those times, revolutionized the way the etiology and pathophysiology of type 2 diabetes was viewed.

The somehow turbulent race to uncover the mechanisms underlying insulin resistance, both in vivo and in vitro, tended to progressively obscure the role of an increase in fat mass due to a positive energy balance.

Therefore, the path that from Hippocrates and Morgagni to Vague and others, led to the dominant thinking that adult diabetes was the result of obesity was interrupted.

Hippocrates wrote: "It is very injurious to health to take in more food than the constitution will bear, when, at the same time one uses no exercise to carry off this excess" [5]; Joannes Baptista Morgagni, some 270 years ago, recognized the association between visceral obesity, hypertension, hyperuricemia, atherosclerosis, and obstructive sleep apnoea syndrome [6]. Finally, Jean Vague, in 1947, pointed again to the central (android) obesity phenotype and its association with diabetes, atherosclerosis, gout, and uric-acid calculus disease [7]. 
However, at those times and in part even nowadays, there was a sort of stigma in considering obesity more than an aesthetic problem due to gluttony and sedentariness, and the endocrinology world welcomed enthusiastically the theory that insulin resistance could have been the primary pathogenic defect to trigger type 2 diabetes or, as called those days, "maturity-onset diabetes". As a matter of fact, way back in 1933, at the annual meeting of the American Physicians and Surgeons in Washington D.C., a renowned scientist introduced his talk by saying: "To be an endocrinologist among the practising profession today means too often to be primarily concerned with making fat ladies thin" [8].

Therefore, in particular until the discovery of leptin in 1992 [9], a milestone for the upsurge interest in adipose tissue, a remarkable amount of research efforts, money and hopes was generated to unveil the basis of insulin resistance. In vivo and in vitro studies on insulin resistance fed each other, floating all the possible scientific spaces of the metabolic arena, thus excluding obesity in the pathogenesis of type 2 diabetes [13-23, 36-40]. With the subsequent growing interest in adipose tissue, the role of increased adiposity progressively regained scientific interest, at least as a risk factor for the development of insulin resistance [10,11].

Historia magistra vitae is a Latin expression, used by Cicero in his De Oratore [12], that means "history (is the) teacher of life" and that conveys the idea that the study of the past should serve as a lesson to the future or, at least, to the present. In this light, we firmly believe that science should not only transform theories in scientific truth when they are rigorously verified but also to dismiss those theories that, even after many decades, become progressively weaker and blurred.

This narrative review, therefore, aims to recapitulate, within an historical perspective encompassing approximately 70 years, the major scientific milestones and hypothesis on the etiopathogenesis of type 2 diabetes, with a specific focus on the putative overestimation of the role of insulin resistance and an underestimation of the role of chronic positive energy balance in the etiopathogenesis of type 2 diabetes.

\section{Insulin resistance: setting the scene}

The breakthrough discovery that plasma insulin concentrations were higher in maturity-onset diabetes compared to non-diabetic individuals after an oral glucose challenge [4], opened a long-lasting season of intense research into both the metabolic and molecular mechanisms underlying this phenomenon. Based on their results Berson and Yalow concluded: "that the tissues of the maturity-onset diabetic do not respond to his insulin as well as the tissues of the nondiabetic subject respond to his insulin": the insulin resistance era was born.
Although many outstanding scientists contributed significantly to the advancement of this new fascinating field in the years that followed [13-17], three of them may well be considered as fathers of insulin resistance: Gerald Reaven, Ralph DeFronzo and, last but certainly not least, Ronald Kahn; all three were recipients of the prestigious Banting Medal for scientific achievement conferred by the American Diabetes Association (ADA) [18-20].

Their many scientific contributions mirrored the main stream thinking on this topic of the last decades of the twentieth century.

\section{Gerald Reaven, the primacy of insulin resistance and the Syndrome $X$}

He pioneered the concept that insulin resistance could be a primary defect leading to compensatory hyperinsulinemia that on one hand may lead to type 2 diabetes when the beta-cells compensatory response declines [21] and, on the other hand, to the "Insulin resistance syndrome" or Syndrome $X$ that increases the cardiovascular risk [18, 22]. In a seminal paper, he demonstrated that $25 \%$ of healthy individuals have a degree of insulin-stimulated glucose uptake that is superimposable to that of type 2 diabetic patients [23]; in other words, he proposed that insulin resistance is prevalent in the normal population and it is not a consequence of the metabolic derangements of uncontrolled diabetes. Those normal subjects primarily insulin resistant are, therefore, at risk of developing type 2 diabetes. In addition, these data demonstrated that insulin resistance precedes the onset of the disease, suggesting that it may be an initial abnormality. One criticism that might be raised to this line of reasoning is that the quartile with the worse insulin sensitivity was composed mainly by males and had a mean body mass index (BMI) that was in part in the overweight range, as typical for North American individuals. Looking at these data today, it is reasonable to assume that the insulin resistance in those individuals defined "healthy", was secondary to the typical combination of chronic caloric surplus and sedentary lifestyle.

As far as the Syndrome $\mathrm{X}$ is concerned, it underwent various reconsideration, reclassifications and critical appraisal [24-28]. We believe that in spite of all the limitations of the various definitions, the one proposed by the International Diabetes Federation [26], i.e., the presence of either obesity or increased waist circumference, is supported by strong evidences linking a state of chronic positive energy balance to the development of all the component of the Metabolic Syndrome (alias Sn. X) [29-31]. Insulin resistance, therefore, is not a primary defect but it develops secondarily to increased fat mass [32-35]. 


\section{Ralph DeFronzo, the glucose clamp: from the triumvirate to the "hateful eight".}

He had the invaluable merit of having developed, together with Jordan Tobin and Reubin Andres, the gold standard for measuring in vivo insulin sensitivity: the euglycemic hyperinsulinemic clamp [36]. This technique, coupled with the use of isotopic tracers, enable also to investigate key metabolic parameters such as hepatic glucose output and insulin secretion. By systematically applying these techniques, DeFronzo, with many other investigators worldwide who had the privilege of being initiated to the holy grail of glucose clamp, drew a sophisticated map of the metabolic fluxes controlled by insulin in both physiological and pathological conditions. These exceptional scientific achievements were brilliantly synthesized during both the ADA 1987 Lilly Lecture [37] and the ADA 2008 Banting Lecture [19]. In 1987, DeFronzo applied a metaphor taken from ancient Rome, the triumvirate (i.e., a board of three officials), to explain the pathogenesis of Type 2 diabetes: insulin resistance in skeletal muscle and liver, and beta-cell failure [37]. In the following 20 years, this view grew to include also fat cell (accelerated lipolysis), gastrointestinal tract (incretin deficiency/resistance), alpha-cell (hyperglucagonemia), kidney (increased glucose reabsorption), and brain (insulin resistance): the ominous octet [19].

From the seminal work of DeFronzo's group [19, 37], as well as of other investigators [38, 39], the leading idea was that skeletal muscle insulin resistance was the major contributing factor to postprandial hyperglycemia in type 2 diabetes, or as defined in those years "non-insulin-dependent diabetes mellitus" (NIDDM), and in part also in the fasting state when liver represents a major site of insulin resistance thus increasing its glucose output. It is noteworthy that, on the basis of the aforementioned results, adipose tissue glucose uptake was assumed to represent around $1 \%$ of total glucose disposal [38, 39]; therefore, fat mass was considered an inert compartment as far as glucose metabolism is concerned. Thus obesity, that contribute to insulin resistance through the increased plasma concentrations of free fatty acids and the consequent enhanced lipid oxidation, was viewed as a special condition somehow distinct from the pathogenetic picture of NIDDM [40].

The conclusion of most scientists at that time was that since NIDDM is a complex disease in which is difficult to identify the primum movens in spite of intense investigations, it must come into play a genetic susceptibility to insulin resistance. In this regard, DeFronzo in 2008 wrote: "Individuals destined to develop type 2 diabetes inherit a set of genes from their parents that make their tissues resistant to insulin ... As long as the beta-cells are able to augment their secretion of insulin sufficiently to offset the insulin resistance, glucose tolerance remains normal. However, with time the beta-cells begin to fail and initially the postprandial plasma glucose levels and subsequently the fasting plasma glucose concentration begin to rise, leading to the onset of overt diabetes" [19].

In the following pages, we will specifically challenge these conclusions since neither data exist that show genes directly inducing insulin resistance in type 2 diabetes nor data that support beta-cells failure secondary to chronic insulin resistance per se in the absence of positive energy balance.

\section{Ronald Kahn, the insulin receptor down-regulation and autophosphorylation, tissue-specific insulin receptor, IRS1 and IRS2 knockout mice}

He made two groundbreaking discoveries (insulin receptor downregulation and autophosphorylation) and many seminal observations, especially those derived from the tissue-specific insulin receptor, IRS1 and IRS2 knockout mice experiments. For these outstanding achievements, he received many prestigious awards; in particular, the Banting Medal for scientific achievement from the American Diabetes Association in 1993 [20] and the George M. Kober Medal from the Association of American Physicians in 2019 [41]. In our opinion, he would have also deserved the Nobel Prize, if it came out that insulin resistance had indeed an etiologic role in the development of type 2 diabetes.

Ronald Kahn began his scientific career in the early seventies at the National Institutes of Health (NIH) under the mentorship of Jesse Roth; in the following years, Roth's lab opened up the all field of receptor biology and insulin signaling; the group was composed of extremely talented scientists that joined NIH also thanks to the Vietnam War. Few alternatives to military service was the Clinical Associate Training Program at the NIH; since only a small percentage of applicants were accepted, this elite program launched an unprecedented number of remarkable scientific careers that would revolutionize medicine at the end of the twentieth century [42]. Therefore, the basic counterpart of in vivo insulin metabolism was particularly powered also by external geopolitical factors.

Later on, Kahn's group applied the Cre-loxP technique [43] to develop a vast array of tissue-specific knockout models of insulin resistance [44]. In particular, the musclespecific insulin receptor knockout (MIRKO) mice provided unexpected results. This mouse model showed no alteration in glucose homeostasis, although it displayed elevated serum triglycerides, free fatty acids and increased visceral fat mass [44]. For the first time, it was recognized that insulin receptor signalling in muscle is not necessary to maintain postprandial glucose disposal in mice.

Overall, these three giants in the field of insulin resistance, contributed significantly in spreading the concept 
that insulin resistance is, or at least may be, the initial defect in type 2 diabetes.

Most of the papers published at that time began with a sentence like the following: "Insulin resistance is a characteristic feature of patients with type 2 diabetes mellitus that precedes the onset of the disease. The presence of insulin resistance leads to increased beta-cell insulin secretion with compensatory hyperinsulinemia. When the beta-cell compensatory response declines type 2 diabetes ensues".

As the molecular mechanisms of insulin signaling were progressively unveiled, all the newly identified molecules were investigated. In many cases skeletal muscle biopsies of patients with overt type 2 diabetes or glucose intolerance were analyzed to measure gene and/or protein expression and function of insulin receptor tyrosine kinase activity, inhibitors of tyrosine kinase activity, insulin receptor isoforms (IR-A and IR-B), insulin receptor substrate (IRS)-1 and IRS-2, phosphatidylinositol 3-kinase (PI3K)AKT, glucose transporter-4 (GLUT-4), just to cite the most important ones [45-51]. These same molecules, and many others, served also as candidate genes to search for variants able to explain the skeletal muscle insulin resistance [52]. It turned out that all the proteins downstream the insulin receptors had a reduction in number and/or of function, but no variants were identified to upgrade them to the role of primary defect responsible for insulin resistance. These are, therefore, secondary defects and may be viewed as molecular effectors of chronic caloric energy balance and/or sedentariness.

As a corollary, we would like to envisage that Ronald Kahn is a case of missing Nobel Prize. In the late sixties, Ronald Kahn took the place of Robert Lefkowitz in the lab of Jesse Roth at NIH. Both were put on a project that aimed at developing a radioligand binding technique to study the adrenal adrenocorticotropic hormone (ACTH) receptor. But it did not work well for both. However, as it always happens for thoroughbreds, they both found their very successful ways. Ronald Kahn began to work with the insulin receptor whereas Robert Lefkowitz with the adrenergic receptors and more in general with G-protein-coupled receptors. They both made unbelievable scientific achievements, becoming soon worldwide recognized absolute leaders in their respective fields. They both received endless number of prestigious awards and medals. However, Robert Lefkowitz was awarded the 2012 Nobel Prize in Chemistry and Ronald Kahn not (yet?). The prize motivation was that approximately half of all medications used today make use of G-protein-coupled receptors.

We believe that if insulin action would have kept the ptolemaic promise of the golden age of being at the center of the metabolic universe, Ronald Kahn would have been awarded too.

\section{Lessons from the human syndromes of insulin resistance}

The syndromes of extreme insulin resistance and the lipodystrophies have taught us two major lessons: 1. the clinical manifestations of true primary insulin resistance; 2 . how secondary insulin resistance may arise from dysfunctional adipose tissue and lipotoxicity.

The following considerations will be made exclusively with the aim to elucidate these two aspects.

\section{Primary extreme insulin resistance syndromes: mutations in the insulin receptor gene.}

Leprechaunism, type A insulin resistance and RabsonMandenhall are the three rare syndromes characterized by mutations in the insulin receptor gene [53]. Leprechaunism bears mutations that impair so severely the insulin receptor function that patients usually die in the first year of life. On the contrary, type A insulin resistance, characterized clinically by acanthosis nigricans and hyperandrogenism, is compatible with a life close to normal. The Rabson-Mendenhall syndrome is defined by the presence of several additive clinical features that include abnormalities of teeth and nails, and pineal hyperplasia; from a clinical point of view, it appears to be intermediate in severity between leprechaunism and type A insulin resistance. Simeon Taylor at the NIH made the first genetic characterization of these patients identifying mutations that affect either the binding affinity to insulin or the activation of the tyrosine kinase in the intracellular portion of the receptor. He pioneered this field under the initial mentorship of Jesse Roth and Phil Gorden [54, 55].

These patients are characterized by marked hyperinsulinemia needed to overcome the genetically dysfunctional insulin receptor. The patients with homozygous mutations are the more resistant and may require several thousand units of insulin per day. However, some of the milder forms (mainly type A insulin resistance) may have close to normal glucose tolerance in spite of congenital markedly elevated plasma insulin concentrations. What happens to their beta-cells after many years of insulin hypersecretion? An answer to this question came from some of the patients studied after 30 years from the initial diagnosis of either type A insulin resistance (n. 8) or with Rabson-Mandenhall syndrome (n. 3) [56]. In particular, two of them with Type A insulin resistance and female were normoglycemic at diagnosis 30 years earlier when they were in their prebubertal-pubertal age. Both had plasma insulin concentration $>250 \mu \mathrm{U} / \mathrm{ml}$ in the fasting state (normal values $<20$ ) and around $1000-2000 \mu \mathrm{U} /$ 
$\mathrm{ml}$ postprandially (normal values $<100$ ). One of the two, 26 years later continued to be normoglycemic and normotolerant with plasma insulin concentrations that continued to range between one hundred and one thousand in the fasting and postprandial state, respectively. The other patient developed only mild impaired glucose tolerance in spite of extremely elevated plasma insulin concentrations. Nine out of the eleven patients were and remained normal weight and were normotrygliceridemic.

Therefore, these data, although obtained in a very limited number of patients, fulfill the proof of concept that primary insulin resistance does not lead necessarily to decline in beta-cell function. In addition, from further studies, it has been confirmed that patients with insulin receptoropathy are normal-weight and protected from developing liver steatosis and the features of metabolic syndrome [57]. As far as body weight is concerned, two robust longitudinal studies carried out either within the San Antonio Heart Study or in the Pima Indians of Arizona, have clearly shown that insulin resistance protects from weight gain $[58,59]$.

\section{Secondary severe insulin resistance syndromes: consequences of pathological adipose tissue deficiency}

During the receptor-centric years it was thought that also the lipoatrophic diabetes (as lipodystrophies were defined at that time) resulted from mutations in the insulin receptor gene [60]. Later on, it became clear that lipodystrophies are caused by a primary selective generalized or partial loss of white adipose tissue [61, 62]. They are a heterogenous group of either genetic or acquired syndromes that, beyond their complex pathogenesis, are all characterized by the absent/ limited adipose tissue storage capacity with consequent ectopic deposition of free fatty acids in skeletal muscle, liver, pancreas, and the visceral adipose tissue (in the partial forms characterized by selective subcutaneous adipose tissue loss) [63]. The chronic lipotoxic environment leads to diabetes mellitus, in the most severe forms recurrent episodes of acute pancreatitis from extreme hypertriglyceridemia, cirrhosis resulting from long-standing hepatic steatosis, and atherosclerotic vascular disease [61].

It is remarkable that the physiopathological picture resulting from the reduction/absence of adipose tissue is superimposable to the typical metabolic syndrome of the overweight/ obese individuals: atherogenic dyslipidemia (hypertriglyceridemia, low HDL cholesterol), impaired glucose tolerance/ overt diabetes, non-alcoholic fatty liver disease (NAFLD).

Therefore, unravelling the aetiopathogenesis of lipodystrophies provided the clear evidence that metabolic syndrome results from a mismatch between the surplus caloric intake and the storage capacity of adipose tissue. White adipose tissue adapts and expands in response to surplus energy through adipocyte hypertrophy and proliferation of precursor cells in combination with vascular and extracellular matrix remodelling. However, in the context of chronic positive energy balance, adipocytes become dysfunctional due to fibro-inflammation processes [64] and the excess energy is redirected toward liver, pancreas [65] and skeletal muscle [66] thus contributing to increased risk of type 2 diabetes and cardiovascular diseases [67]. Furthermore, the adiposopathy (sick fat) concept explains why not all persons with overweight or obesity develop type 2 diabetes: it is not the amount of fat but its quality that is metabolically detrimental.

In summary, these two human models contributed significantly in highlighting the role of primary insulin resistance versus the secondary metabolic derangements due to inadequate energy storage capacity. Insulin resistance per se, as inferred from the insulin receptoropathies, is devoid of any effect on fat mass, triglycerides and HDL cholesterol; in addition, NAFLD is absent and it is, at present, unknown if it exerts any effect on the vasculature (Table 1).

\section{How the Pima Indians challenged the primacy of insulin resistance in the development of type 2 diabetes}

Although beta-cell failure was always included in the definition of type 2 diabetes, the disease has been traditionally understood as a metabolic disorder initiated by insulin resistance. This view was necessarily reconsidered when, in 1999, data were published on the temporal sequence

Table 1 Anthropometric, metabolic and hormonal differences between obesity, lipodystrophies and insulin receptoropathy

\begin{tabular}{llll}
\hline Characteristics & $\begin{array}{l}\text { Obesity } \uparrow \text { (with } \\
\text { Metabolic Syn- } \\
\text { drome) }\end{array}$ & Lipodystrophies & $\begin{array}{l}\text { Insulin } \\
\text { receptoro- } \\
\text { pathy }\end{array}$ \\
\hline BMI & $\uparrow$ & $\downarrow$ & $\leftrightarrow$ \\
Body fat \% & $\uparrow$ & $\downarrow \downarrow \downarrow$ & $\leftrightarrow$ \\
Waist (cm) & $\uparrow$ & $\leftrightarrow \downarrow$ & $\leftrightarrow$ \\
Hip (cm) & Relative $\downarrow$ & $\downarrow \downarrow$ & $\leftrightarrow$ \\
Waist/hip ratio & $\uparrow \uparrow$ & $\uparrow \uparrow$ & $\leftrightarrow$ \\
Insulin resistance & $\uparrow$ & $\uparrow \uparrow$ & $\uparrow \uparrow \uparrow$ \\
Triglycerides & $\uparrow$ & $\uparrow \uparrow$ & $\leftrightarrow$ \\
HDL cholesterol & $\downarrow$ & $\downarrow$ & $\leftrightarrow$ \\
Leptin & $\uparrow \uparrow$ & $\downarrow \downarrow \downarrow / \downarrow$ & $\leftrightarrow$ \\
NAFLD & $\uparrow$ & $\uparrow \uparrow$ & Absent \\
PCOS & $\uparrow$ & $\uparrow \uparrow$ & $\uparrow \uparrow$ \\
Atherosclerosis & $\uparrow$ & $\uparrow \uparrow$ & Unknown \\
\hline
\end{tabular}

Modified from [63]

NAFLD non-alcoholic fatty liver disease, $P C O S$ polycystic ovary syndrome 
with which these metabolic abnormalities develop relative to one another during the different stages of the disease. The authors measured insulin action, insulin secretion, and hepatic glucose production longitudinally in Pima Indians, in whom glucose tolerance deteriorated from normal to impaired to diabetic over several years [68]. They demonstrated that as long as the insulin secretory response increases to compensate for the worsening of insulin sensitivity, subjects remain normoglycemic. The progression toward impaired glucose tolerance and frank diabetes is totally accounted for by impaired insulin secretion (Fig. 1).

\section{Did genetic help in solving the apparent conundrum?}

At the end of the nineties, the leading hypothesis was that type 2 diabetes represented a definite and complex nosographic entity caused by the interplay of insulin resistance and beta cell failure. Obesity and environmental factors had additive deleterious, though aetiologically marginal, effects. As high-density single nucleotide polymorphism arrays (SNPs) became available for launching genome-wide association scans in large case-control cohorts, optimism pervaded the field. However, results did not go in the direction expected. In synthesis, 1 . the larger genome-wide association studies (GWAs) identified loci with an effect size that barely goes beyond odd ratios of one (with very few exceptions) and, therefore, that confer a very small risk [69-72]; 2. most of the risk SNPs affect beta-cell function favouring a beta-cell-centric view on the genetics of type 2 diabetes [73].

Moreover, in an attempt to look for loci associated with insulin resistance phenotypes, a group headed by Stephen

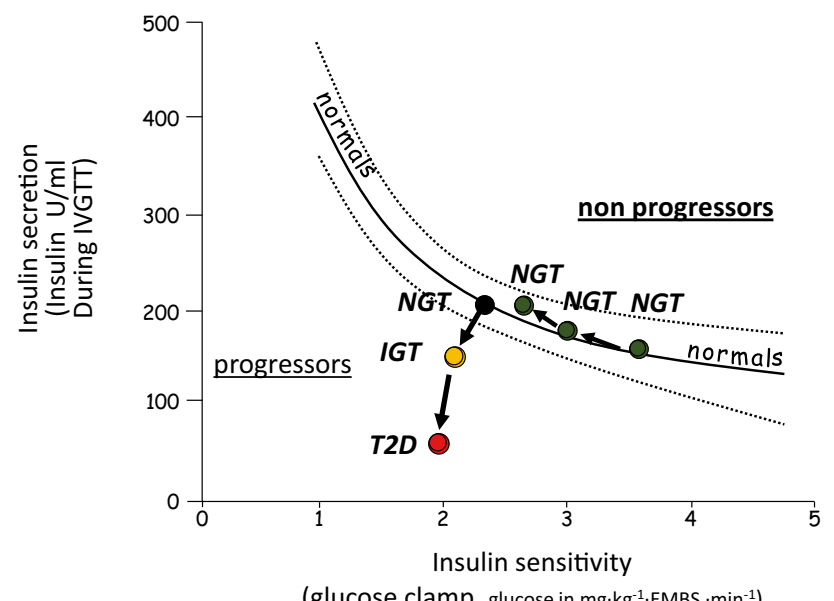

(glucose clamp, glucose in $\mathrm{mg} \cdot \mathrm{kg}-1 . \mathrm{EMBS} \cdot \mathrm{min}^{-1}$ )

Fig. 1 Insulin secretion and sensitivity changes and progression toward type 2 diabetes in Pima Indians. NGT normal glucose tolerance, IGT impaired glucose tolerance, $T 2 D$ type 2 diabetes, EMBS estimated metabolic body size. Modified from [68]
O'Rahilly and Robert Scott from the University of Cambridge, using an integrative genomic approach, identified 53 genomic regions associated with a limited capacity to store fat in a healthy way [74]. Therefore, also under a genetic point of view, insulin resistance appears a secondary hallmark of a dysfunctional adipose tissue.

Of particular interest were those studies that investigated the genetic-lifestyle interaction to disentangle their relative contribution to confer risk of developing type 2 diabetes. To this end and taking advantage of the large EPIC InterAct Case-Cohort Study (12,403 incident type 2 diabetes cases from a cohort of 340,234 European participants with 3.99 million person-years of follow-up) Langenberg et al. were able to show that modifiable factors, particularly obesity, outweighed genetic risk scores in conferring absolute risk of developing type 2 diabetes. Obese individuals in the lowest genetic risk quartile were much more likely to develop type 2 diabetes than normal weight individuals in the highest genetic risk quartile (Fig. 2), indicating that if only genetics had been used for risk stratification, the individuals at highest risk would not have been targeted for intervention [75]. Similarly, in a case-cohort study carried out in Denmark, obesity and unfavourable lifestyle were associated with higher risk for incident type 2 diabetes regardless of genetic predisposition [76].

Therefore, the various genetic loci that were identified thanks to very large GWAs, mainly involved in insulin secretion rather than in insulin sensitivity, confer a modest susceptibility risk to develop type 2 diabetes, whereas obesity represents the strongest predictor.

\section{From bariatric surgery DiRECTly toward type 2 diabetes reversibility}

Surgeons learned, over the years, that type 2 diabetes is a complex heterogeneous disease mainly driven by insulin resistance with a genetic predisposition, inevitably progressive despite glucose-lowering treatment, with $50 \%$ of individuals requiring insulin therapy within 10 years [77]. Therefore, it is not surprising that when they documented a complete withdrawal of all antihyperglycemic medications, including high dosage insulin, few weeks after a bariatric surgery intervention and well ahead of any significant weight loss, they claimed that something intrinsically to the intervention cured the disease [78, 79]. From this initial observation, a huge florilegium of hypothesis was put forward trying to explain the antidiabetic mechanisms of bariatric surgery [80]. However, it was completely overlooked a remarkable metabolic change that occurs after surgery, in particular during the first weeks: a striking decrease in caloric intake. This effect translates in profound changes in metabolic fluxes and intracellular handling of nutrients, 
Fig. 2 Risk of type 2 diabetes in relation of quartiles of genetic risk score and weight status. Modified from [75]

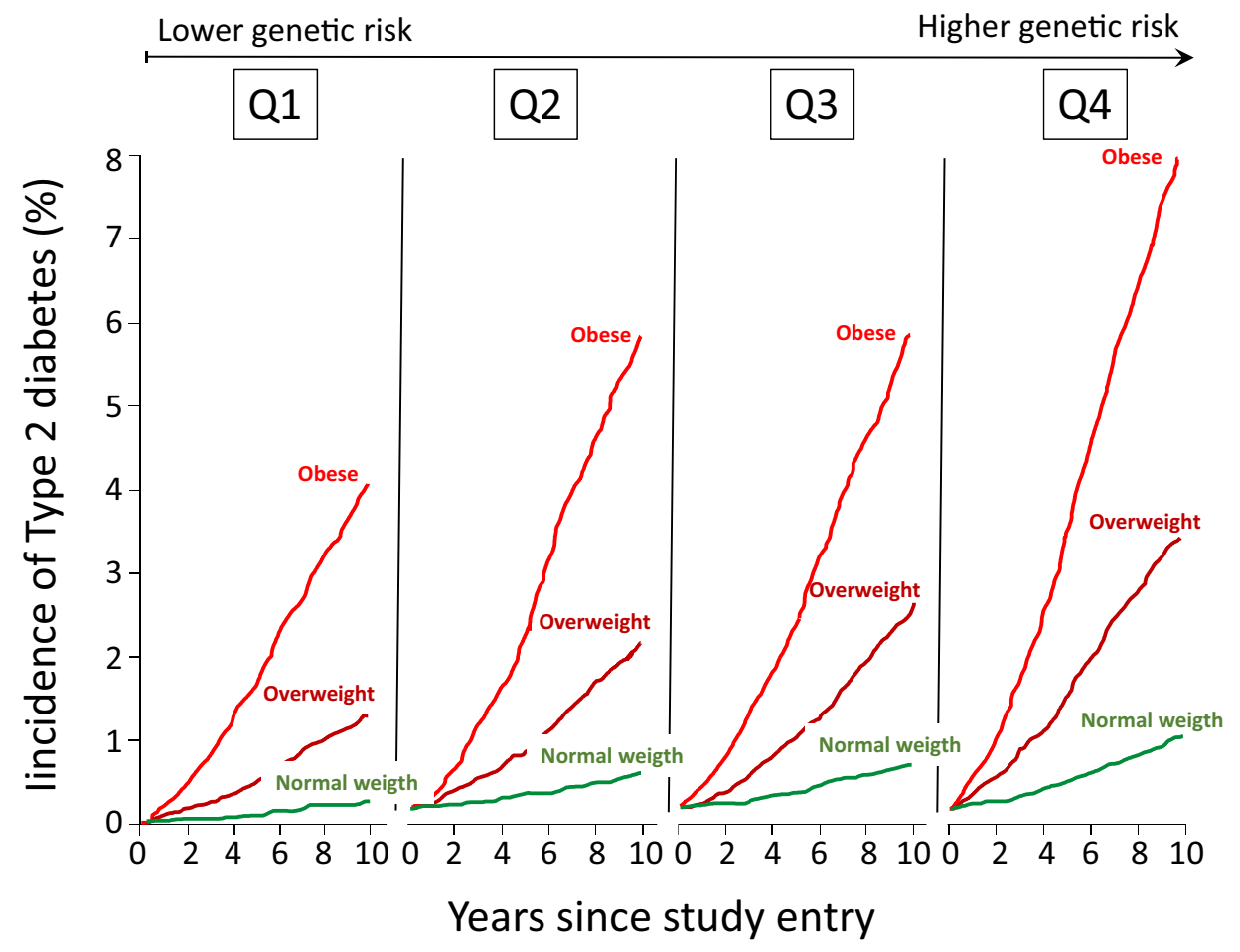

in particular fat metabolites. To test the hypothesis that by reducing caloric intake, insulin resistance and beta-cell failure can be reversed, Roy Taylor and his group measured basal hepatic glucose output, hepatic and peripheral insulin sensitivity, beta cell function, and pancreas and liver triacylglycerol content in a small group of patients with type 2 diabetes before and during a very-low-calorie diet (VLCD) [81]. Quite surprisingly, within 7 days, liver fat decreased becoming similar to that of the control group, and hepatic insulin sensitivity normalized. Plasma glucose normalized by day 7 of the diet (Fig. 3). It is worth noting that, in spite of these striking results, peripheral insulin-mediated glucose disposal, as measured by glucose clamp, remained unchanged during the 8 weeks of the study. This seminal observation paved the way to further studies $[82,83]$ and led to a remarkable paradigm shift: type 2 diabetes is a reversible disease.

To confirm these results in a larger and more robust setting, 298 type 2 diabetic patients were randomized into the Diabetes Remission Clinical Trial (DiRECT) to receive either a weight management programme (that included a low energy formula diet of $825-853 \mathrm{kcal} /$ day for 3 months) or a best-practice care by guidelines as control. After 1 year almost half of participants in the intervention arm achieved remission to a non-diabetic state and off antidiabetic drugs [84]. Moreover, by stratifying the remissions rate by the amount of weight loss at 12 months, it was shown that the remission rate in those who lost $\geq 15 \mathrm{~kg}$ was close to $90 \%$ (Fig. 4). Therefore, beyond the proof of concept, remission of type 2 diabetes may represent also a practical target. This
Fig. 3 Effect of 8 weeks of very-low-calorie diet (VLCD) on plasma glucose (left panel) and basal hepatic glucose production (right panel). White circles and blue lines (C) indicate the mean for the weightmatched non-diabetic control group. Modified from [81]
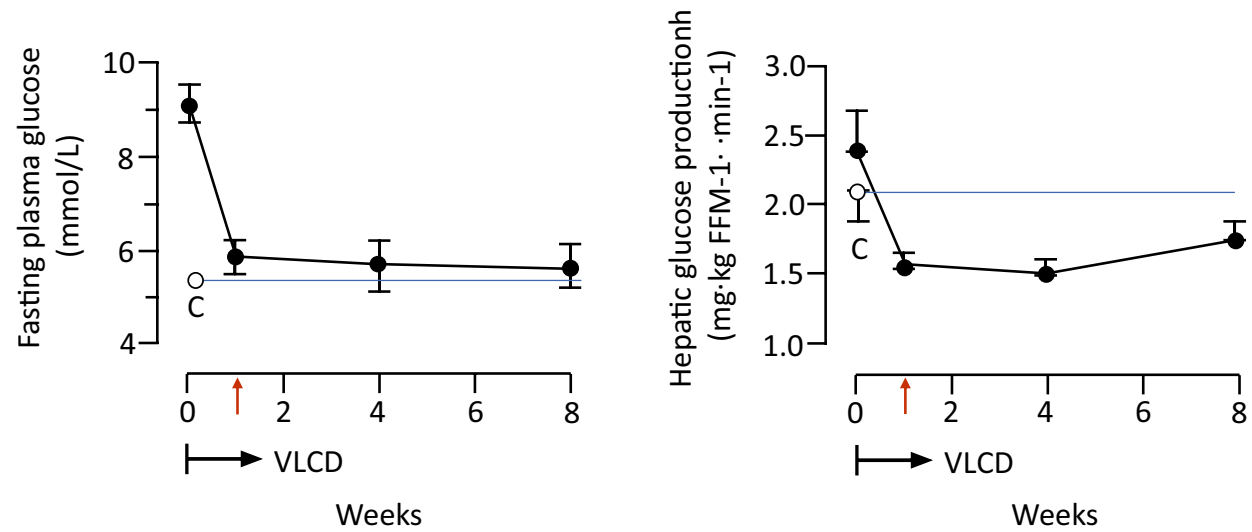


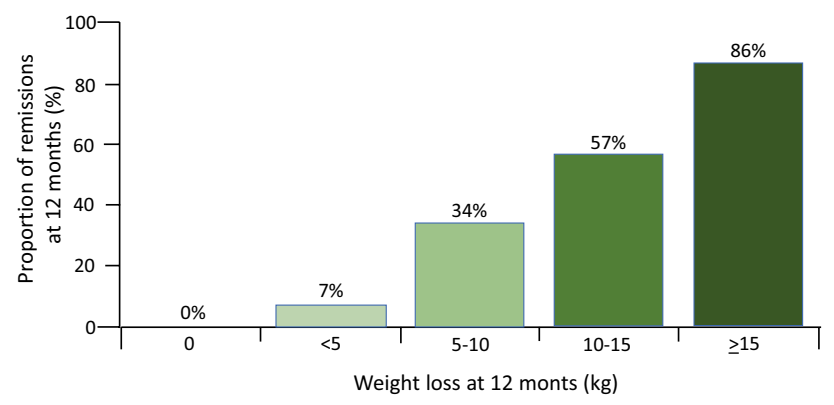

Fig. 4 Remission of diabetes in relation to weight loss at 12 months of the DiRECT trial. Modified from [84]

result was further corroborated in two recent studies that compared the metabolic effects of a VLCD versus Roux-en$\mathrm{Y}$ gastric bypass in type 2 diabetic patients; the metabolic improvements were identical in the two group, ruling out any mechanism intrinsic to the surgical operation and confirming the reversibility of type 2 diabetes $[85,86]$.

These data strengthen the concept that type 2 diabetes is caused by a chronic condition of positive energy balance with the consequent deposition of caloric surplus in liver and pancreas when adipocytes become dysfunctional. As long as the beta-cells are not irreversibly damaged by long-lasting disease [87], the induction of a negative energy balance is able to reverse type 2 diabetes.

\section{Type 2 diabetes and the "metabolically obese" normal weight individuals: the role of fat distribution}

Abdominal obesity is more closely associated with the risk of developing type 2 diabetes and several studies have suggested that waist circumference or the waist-to-hip ratio may be better predictors than BMI [88-90]. BMI has two major limitations: it is not a measure of fat mass, and it does not convey any information on fat distribution and regional fat depots, and for any given BMI, percentage body fat [91, 92] and fat distribution can vary substantially. This led to the identification, in terms of risk of developing the metabolic syndrome and type 2 diabetes, of two opposite phenotypes: the "metabolically healthy" obese individuals and the "metabolically obese" normal weight individuals [93, 94]. This latter phenotype is characterized by $\mathrm{BMI}<25$ but increased percentage body fat and increased waist circumference [95]. Therefore, not only the majority of individuals with type 2 diabetes are overweight or obese, but also the majority of type 2 diabetic patients with $\mathrm{BMI}<25$ have increased fat depots [95]. Moreover, if we consider that the majority of type 2 diabetic patients who are truly lean have positive islet cell antibodies and/or insulin autoantibodies belonging, therefore, to the LADA group of patients [96], the remaining bona fide type 2 diabetic patients with $\mathrm{BMI}<25$ and normal body composition with no secondary etiologies (pancreatopathies, endocrinopathies, etc.) represents a tiny portion that need further investigations.

\section{Is it time to revise the classification of diabetes?}

WHO classification of diabetes moved from an age-related definition (e.g., maturity-onset) in 1965, to a therapeuticrelated definition (e.g., non-insulin dependent diabetes mellitus - NIDDM) in 1980 and finally, in 1999, introduced the actual categorical division in type 1 and type 2 diabetes [97]. While the American Diabetes Association states that: "Type 2 diabetes is due to a progressive loss of b-cell insulin secretion frequently on the background of insulin resistance" [98], WHO at least acknowledges that it is: "commonly associated with overweight and obesity" [97].

There are some genetic and many secondary causes of diabetes that resemble type 2 diabetes, like monogenic defects of $\beta$-cell function (MODY), latent autoimmune diabetes of the adult (LADA), diseases of the exocrine pancreas, endocrinopathies, drug- or chemical-induced forms, hemochromatosis, etc., but these represents a tiny portion in comparison of the huge pandemic numbers of type 2 diabetic patients that are overweight, obese or that, even if their $\mathrm{BMI}$ is below 25, have increased fat depots as a result of a slight but chronic positive energy balance. In this setting the concept of personal fat threshold proposed by Taylor and Holman [99], may be applied. They hypothesize that each individual has a personal fat threshold, independent of BMI, which, if exceeded, increases the likelihood to develop type 2 diabetes. Subsequent weight loss to take the individual below their level of susceptibility should allow return to normal glucose control. The concept of personal fat threshold may be of practical benefit in explaining the onset of diabetes in the non-obese people with type 2 diabetes. For all the data produced, in particular in the last two decades and in part reviewed here, is incorrect to say that type 2 diabetes "associates" with obesity but rather is time to acknowledge that it is caused by overweight and obesity or, in general, by an increase fat mass in the visceral depots as a sign of positive energy balance.

Therefore, it would be reasonable to move toward an etiologic definition. We recognize that it is not an easy task to identify a concise and clear etiologic definition, but we believe that this would translate in a remarkable help in better prevent, treat and, may be, reverse the disease. To say to a patient: "you have a type $\mathrm{x}$ disease" is the perfect way to create an initial barrier. We would like to propose the definition "adiposity-based diabetes", although we recognize that 
it could be more elegant to utilize the definition that Eleazar Shafrir and Itamar Raz proposed in 2003: diabetes lipidus [100]. Both definitions, pointing to the energy surplus as the primum movens, would have the advantage to encompass the full spectrum of adiposopathy, irrespectively of BMI: from lipodystrophies with low BMI to severe obesity (Fig. 5).

\section{Have diagnostic procedure and/ or pharmacologic therapy been targeted to insulin sensitivity?}

The glucose clamp [36] is the gold standard for the measurement of insulin sensitivity but it is quite complex and time-consuming; many others simpler indices have been developed over the years [101] that however, although validated against the reference method, have little value in the single individual.

Today, there is no routinely and validated diagnostic methods to measure insulin sensitivity and, above all, there is no practical need to such a measurement, neither to predict type 2 diabetes nor to monitor the glycemic and metabolic control once the disease ensues.

As far as drugs affecting insulin sensitivity are concerned, metformin has been considered for many years one of such drugs; however, at the whole-body level, metformin itself does not affect insulin sensitivity in muscle or adipose tissue [102]. Instead, it has been shown to inhibit hepatic gluconeogenesis [103].

The only class of antihyperglycemic drugs that increases insulin sensitivity as principal mode of action is that of thiazolidinediones [104]. However, they enhance insulin sensitivity indirectly and fit well as drugs for the treatment of hyperglycemic conditions characterized by dysfunctional adipose tissue. Being ligands for peroxisome proliferator-activated receptor (PPAR)-gamma, a nuclear hormone receptor expressed predominantly in adipose tissue, they increase the number of small adipocytes in white adipose tissue, thus counteracting the fibro-inflammatory transformations of large adipocytes and enhancing the storage potential of the energy surplus [105].

To the best of our knowledge, there are no direct insulin sensitizers (i.e., molecules that stimulate insulin signalling) in pharmaceutical pipelines. Such drugs, in the face of continuous positive energy balance, would lead to intracellular hypermetabolism in insulin target tissues with possible deleterious effects; not mentioning the possibility of increasing the cancer risk due to proliferative and antiapoptotic effects.

Therefore, after half a century from the initial modern definition, insulin resistance did not add any clinical tool or treatment in the management of type 2 diabetes.

\section{Conclusions}

Adiposity, sedentariness and age are the major contributors to the development of insulin resistance. In severe cases, acanthosis nigricans may develop as well as hyperandrogenism and polycystic ovary syndrome in females. Moreover, hyperinsulinemia may exert potent proliferative effects, either directly or by cross-reacting with the insulin-like growth factor 1 (IGF-1) receptor $[14,106]$ thus increasing the risk of cancer in obesity and type 2 diabetes.

It is not our intention to underestimate the pathophysiological role of insulin resistance, but rather to counteract the overestimation that took place in the past and that, by inertia,
Fig. 5 Etiopathogenesis of type 2 diabetes: the old (a) and new (b) flow charts

\section{ETIOPATHOGENESIS OF TYPE 2 DIABETES}

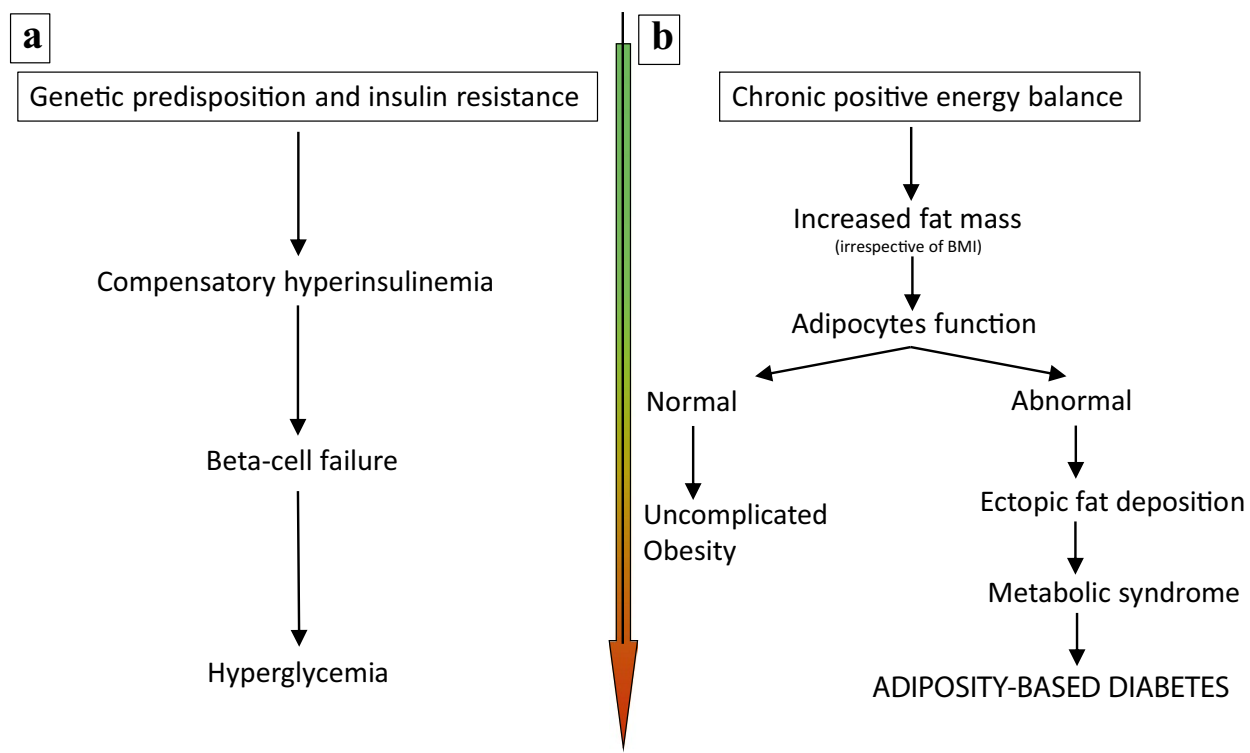


continue somehow nowadays. Insulin resistance became a myth and myths are hard to dispel. However, science has the duty to combat myths and dogmas; these are enemies of the scientific method and its empirism.

A huge amount of scientific evidences has been produced, part of which are presented herein, that clearly demonstrated that peripheral insulin resistance is devoid of the pivotal physiopathological role originally proposed. This concept began to be hypothesized years ago [107]. More recently, obesity was recognized as associated with increased basal and postprandial beta-cell insulin secretion even in the absence of insulin resistance [108]. In this sense, increased insulin secretion in obese subjects appears associated with excess adiposity itself and not simply a compensatory response to insulin resistance.

In summary, the data discussed in this review show that type 2 diabetes is mostly caused by a chronic condition of positive energy balance with the consequent deposition of caloric surplus in liver and pancreas when adipocytes become dysfunctional and, as long as the beta-cells are not irreversibly damaged by long-lasting disease [87], the induction of a negative energy balance is able to reverse type 2 diabetes.

In conclusion, is time to change the dogma, type 2 diabetes is not "often associated with overweight or obesity" but overweight or obesity often cause type 2 diabetes.

\section{What is already known on this subject?}

Type 2 diabetes is defined as a complex nosographic entity caused by the interplay of insulin resistance and beta cell failure. Although increased fat deposition is always been regarded as a major risk factor, its etiological role have never been fully recognized.

\section{What does this study add?}

To the best of our knowledge this is the first time that, within an historical perspective, data from lipodystrophies, receptoropathies, genetic studies and trials on diabetes reversibility have been put together to redraw the etiology of type 2 diabetes.

This review reappraises the role of insulin resistance in the development of type 2 diabetes and provide strong evidences that hyperglycemia ensues when caloric surplus in the form of fat, that no longer can be stored in adipose tissue, infiltrates liver and pancreas, progressively blunting insulin secretion. As long as the beta-cells are not irreversibly damaged by long-lasting disease, the induction of a negative energy balance is able to reverse type 2 diabetes. Reversibility rules out intrinsic/genetic defects pointing strongly to chronic positive energy balance being the cause.
Funding Open Access funding provided by Università degli Studi di Roma Tor Vergata. This work was supported in part by a grant from the Ministero dell'Istruzione, dell'Università e della Ricerca (prot.2017L8Z2EM).

\section{Compliance with ethical standards}

Conflict of interest The authors declare no conflict of interest.

Research involving human participants and/or animals The present study does not involve human and/or animal participants.

Informed consent Informed consents are not applicable.

Open Access This article is licensed under a Creative Commons Attribution 4.0 International License, which permits use, sharing, adaptation, distribution and reproduction in any medium or format, as long as you give appropriate credit to the original author(s) and the source, provide a link to the Creative Commons licence, and indicate if changes were made. The images or other third party material in this article are included in the article's Creative Commons licence, unless indicated otherwise in a credit line to the material. If material is not included in the article's Creative Commons licence and your intended use is not permitted by statutory regulation or exceeds the permitted use, you will need to obtain permission directly from the copyright holder. To view a copy of this licence, visit http://creativecommons.org/licenses/by/4.0/.

\section{References}

1. Insulin Resistance and Sensitivity (1940) Br Med J 1(4139):734. https://www.ncbi.nlm.nih.gov/pmc/articles/PMC2177405/

2. Lozinski E, Frohlich LI (1942) Resistance to Insulin. Can Med Assoc J 46(1):62-65

3. Yalow RS, Berson SA (1960) Immunoassay of endogenous plasma insulin in man. J Clin Invest 39(7):1157-1175

4. Yalow R, Berson SA (1960) Plasma insulin concentrations in nondiabetic and early diabetic subjects. Determinations by a new sensitive immuno-assay technic. Diabetes 9:254-260

5. Hippocrates $\sim 400 \mathrm{bc}$ De Flatibus.

6. Enzi G, Busetto L, Inelmen EM, Coin A, Sergi G (2003) Historical perspective: visceral obesity and related comorbidity in Joannes Baptista Morgagni's 'De sedibus et causis morborum per anatomen indagata'. Int J Obes Relat Metab Disord 27:534-535

7. Vague J (1956) The degree of masculine differentiation of obesities: a factor determining predisposition to diabetes, atherosclerosis, gout, and uric calculous disease. Am J Clin Nutr 4:20-34

8. Lisser H (1967) The first forty years (1917-1957). Fiftieth Anniv Issue Endocrinol 80:5-28

9. Zhang Y, Proenca R, Maffei, (1994) Barone M, Leopold L, Friedman JM Positional cloning of the mouse obese gene and its human homologue. Nature 372:425-431

10. Kahn SE, Cooper ME, Del Prato S (2014) Pathophysiology and treatment of type 2 diabetes: perspectives on the past, present, and future. Lancet 383:1068-1083

11. Kahn BB, Flier JS (2000) Obesity and insulin resistance. J Clin Invest 106:473-481

12. De Oratore, Cicero, II, 9, 36, 54 BC

13. Saltiel A, Kahn CR (2001) Insulin signalling and the regulation of glucose and lipid metabolism. Nature 414:799-806

14. Kubota T, Kubota N, Kadowaki, (2017) Imbalanced insulin actions in obesity and type 2 diabetes: key mouse models of insulin signaling pathway. Cell Metab 25:797-810 
15. Taylor SI (1999) Deconstructing type 2 diabetes. Cell 97:9-12

16. DeFronzo RA, Del Prato S (1996) Insulin resistance and diabetes mellitus. J Diabetes Complic 10:243-245

17. Sesti G, Federici M, Lauro D, Sbraccia P, Lauro R (2001) Molecular mechanism of insulin resistance in type 2 diabetes mellitus: role of the insulin receptor variant forms. Diabetes Metab Res Rev 17:363-373

18. Reaven GM (1988) Banting Lecture 1988: Role of insulin resistance in human disease. Diabetes 37:1595-1607

19. DeFronzo RA (2009) Banting Lecture 2008. from the triumvirate to the ominous octet: a new paradigm for the treatment of type 2 diabetes mellitus. Diabetes 58:773-795

20. Kahn CR (1994) Banting lecture 1993: insulin action, diabetogenes, and the cause of type II diabetes. Diabetes 43:1066-1085

21. Reaven GM (2005) Insulin resistance, type 2 diabetes mellitus, and cardiovascular disease. The End Begin Circ 112:3030-3032

22. Reaven GM (2005) Why syndrome X? From Harold Himsworth to the insulin resistance syndrome. Cell Metab 1:9-14

23. Hollembeck C, Reaven GM (1987) Variations in insulin-stimulated glucose uptake in healthy individuals with normal glucose tolerance. J Clin Endocrinol Metab 64:1169-1173

24. World Health Organization Definition, diagnosis and classification of diabetes mellitus and its complications. Part 1: diagnosis and classification of diabetes mellitus. WHO (1999), Geneva.

25. Grundy SM, Brewer HB Jr, cleeman JI, Smith SC Jr, Lenfant C (2004) Definition of metabolic syndrome: Report of the National Heart, Lung, and Blood Institute/American Heart Association conference on scientific issues related to definition. Circulation 109:433-438

26. Alberti KG, Zimmet SJ (2005) The metabolic syndrome-a new worldwide definition. Lancet 366:1059-1062

27. Alberti KG, Eckel RH, Grundy SM et al (2009) Harmonizing the Metabolic syndrome. A Joint Interim Statement of the International Diabetes Federation Task Force on Epidemiology and Prevention; National Heart, Lung, and Blood Institute; American Heart Association; World Heart Federation; International Atherosclerosis Society; and International Association for the Study of Obesity. Circulation 120:1640-1645

28. Kahn R, Buse J, Ferrannini E, Stern M (2005) The metabolic syndrome: time for a critical appraisal. Joint statement from the American Diabetes Association and the European Association for the Study of Diabetes. Diabetologia 48:1684-1699

29. Opie LH (2007) Metabolic syndrome. Circulation 115:e32-e35

30. Czech MP (2017) Insulin action and resistance in obesity and type 2 diabetes. Nature Med 23:804-814

31. Samuel VT, Shulman GI (2016) The pathogenesis of insulin resistance: integrating signaling pathways and substrate flux. $\mathbf{J}$ Clin Invest 126:12-22

32. Kahn CR, Wang G, Lee KY (2019) Altered adipose tissue and adipocyte function in the pathogenesis of metabolic syndrome. J Clin Invest 129:3990-4000

33. Kim JY, van de Wall E, Laplante M, Azzara A, Trujillo ME, Hofmann SM, Schraw T, Durand JL, Li H, Li G, Jelicks LA, Mehler MF, Hui DY, Deshaies Y, Shulman GI, Schwartz GJ, Scherer PE (2007) Obesity-associated improvements in metabolic profile through expansion of adipose tissue. J Clin Invest 117:2621-2637

34. Virtue S, Vidal-Puig A (2008) It's not how fat you are, it's what you do with it that counts. PLoS Biol 6:e237

35. Shulman GI (2014) Ectopic fat in insulin resistance, dyslipidemia, and cardiometabolic disease. N Engl J Med 371:1131-1141

36. DeFronzo RA, Tobin JD, Andres R (1979) Glucose clamp technique: a method for quantifying insulin secretion and resistance. Am J Physiol 237:E214-223
37. DeFronzo RA (1988) Lilly lecture 1987. The triumvirate: betacell, muscle, liver. A Collusion Respons NIDDM Diabetes 37:667-687

38. Bjorntorp P, Sjostrom L (1978) Carbohydrate storage in man: speculations and some quantitative considerations. Metabolism 27(Suppl. 2):1853-1865

39. Bjorntorp P, Berchtold P, Holm J (1971) The glucose uptake of human adipose tissue in obesity. Eur J Clin Invest 1:480-485

40. Williamson JR, Kreisberg RA, Felts PW (1966) Mechanism for the stimulation of gluconeogenesis by fatty acids in perfused rat liver. Proc Natl Acad Sci USA 56:247-254

41. Flier JS (2019) Association of American Physicians George M. Kober Medal Presentation C. Ronald Kahn: the Louisville Slugger of metabolic science. J Clin Invest 129:5066-5070

42. Greenberg RS (2020) Medal winners: how the Vietnam war launched nobel careers. Univ of Texas Press, Austin

43. Gu H, Marth JD, Orban PC, Mossmann H, Rajewsky K (1994) Deletion of a DNA polymerase beta gene segment in T cells using cell type-specific gene targeting. Science 265:103-106

44. Mauvais-Jarvis F, Kulkarni RN, Kahn CR (2002) Knockout models are useful tools to dissect the pathophysiology and genetics of insulin resistance. Clin Endocrinol 57:1-9

45. Haring H, Obermaier-Kusser B (1989) Insulin receptor kinase defects in insulin-resistant tissues and their role in the pathogenesis of NIDDM. Diabetes Metab Rev 5:431-441

46. Maddux BA, Sbraccia P, Kumakura S, Sasson S, Youngren J, Fisher A, Spencer S, Grupe A, Henzel W, Stewart TA et al (1995) Membrane glycoprotein PC-1 and insulin resistance in non-insulin-dependent diabetes mellitus. Nature 373:448-451

47. Mosthaf L, Vogt B, Häring HU, Ullrich A (1991) Altered expression of insulin receptor types A and B in the skeletal muscle of non-insulin-dependent diabetes mellitus patients. Proc Natl Acad Sci U S A 88(11):4728-4730

48. Withers DJ, Gutierrez JS, Towery H et al (1998) Disruption of IRS-2 causes Type 2 diabetes in mice. Nature 391:900-904

49. Mauvais-Jarvis F, Ueki K, Fruman DA, Hirshman M, Sakamoto K, Goodyear LJ, Iannacone M, Accili D, Cantley LC, Kahn CR (2002) Reduced expression of the murine p85alpha subunit of phosphoinositide 3-kinase improves insulin signaling and ameliorates diabetes. J Clin Invest 109:141-149

50. Shepherd PR, Kahn BB (1999) Glucose transporters and insulin action. Implications for insulin resistance and diabetes mellitus. N Engl J Med 341:248-257

51. Whithers DJ, White M (2000) Perspective: the insulin signaling system-a common link in the pathogenesis of type 2 diabetes. Endocrinology 141:1917-1921

52. Hansen L, Zethelius B, Berglund L, Reneland R, Hansen T, Berne C, Lithell H, Hemmings BA, Pedersen O (2001) In vitro and in vivo studies of a naturally occurring variant of the human p85alpha regulatory subunit of the phosphoinositide 3-kinase: inhibition of protein kinase $\mathrm{B}$ and relationships with type 2 diabetes, insulin secretion, glucose disappearance constant, and insulin sensitivity. Diabetes 50:690-693

53. Taylor SI, Cama A, Accili D, Barbetti F, Quon MJ, de la Luz SM, Suzuki Y, Koller E, Levy-Toledano R, Wertheimer E et al (1992) Mutations in the insulin receptor gene. Endocr Rev 13:566-595

54. Taylor SI, Hedo JA, Underhill LH, Kasuga M, Elders MJ (1982) Roth J. Extreme insulin resistance in association with abnormally high binding affinity of insulin receptors from a patient with leprechaunism: evidence for a defect intrinsic to the receptor. J Clin Endocrinol Metab 55:1108-1113

55. Grunberger G, Taylor SI, Dons RF, Gorden P (1983) Insulin receptors in normal and disease states. Clin Endocrinol Metab $12: 191-219$ 
56. Musso C, Cochran E, Moran SA, Skarulis MC, Oral EA, Taylor S, Gorden P (2004) Clinical course of genetic diseases of the insulin receptor (type A and Rabson-Mendenhall syndromes): a 30-year prospective. Medicine 83:209-222

57. Semple RK, Savage DB, Cochran EK, Gorden P, O'Rahilly S (2011) Genetic syndromes of severe insulin resistance. Endocr Rev 32:498-514

58. Valdez R, Mitchell BD, Haffner SM, Hazuda HP, Morales PA, Monterrosa A, Stern MP (1994) Predictors of weight change in a bi-ethnic population. The San Antonio Heart Study. Int J Obes Relat Metab Disord 18:85-91

59. Swinbum BA, Nyomba BL, Saad MF, Zurlo F, Raz I, Knowler WC, Lillioja S, Bogardus C, Ravussin E (1991) Insulin resistance associated with lower rates of weight gain in Pima Indians. J Clin Invest 88:168-173

60. Kriauciunas K, Kahn CR, Muller-Wieland D, Reddy SS, Taub $\mathrm{R}$ (1988) Altered expression and function of the insulin receptor in a family with lipoatrophic diabetes. J Clin Endocrinol Metab 67:1284-1293

61. Garg A (2004) Acquired and Inherited Lipodystrophies. N Engl J Med 350:1220-1234

62. Novelli G, Muchir A, Sangiuolo F, Helbling-Leclerc A, D’Apice MR, Massart C, Capon F, Sbraccia P, Federici M, Lauro R et al (2002) Mandibuloacral dysplasia is caused by a mutation in LMNA-encoding lamin A/C. Am J Hum Genet 71:426-431

63. MannJP SDB (2019) What lipodystrophies teach us about the metabolic syndrome. J Clin Invest 129:4009-4021

64. Guglielmi V, Cardellini M, Cinti F, Corgosinho F, Cardolini I, D’Adamo M, Zingaretti MC, Bellia A, Lauro D, Gentileschi P, Federici M, Cinti S, Sbraccia P (2015) Omental adipose tissue fibrosis and insulin resistance in severe obesity. Nutr Diabetes 5:e175

65. Guglielmi V, Sbraccia P (2018) Type 2 diabetes: Does pancreatic fat really matter? Diabetes Metab Res Rev 34:2

66. Guglielmi V, Sbraccia P (2018) Obesity phenotypes: depotdifferences in adipose tissue and their clinical implications. Eat Weight Disord 23:3-14

67. Fall T, Hägg S, Mägi R, Ploner A et al (2013) The role of adiposity in cardiometabolic traits: a Mendelian randomization analysis. PLoS Med 10:e1001474

68. Weyer C, Bogardus C, Mott DM, Pratley RE (1999) The natural history of insulin secretory dysfunction and insulin resistance in the pathogenesis of type 2 diabetes mellitus. J Clin Invest 104:787-794

69. Saxena R, Voight BF, Lyssenko V, Burtt NP et al (2007) Genomewide association analysis identifies loci for type 2 diabetes and triglyceride levels. Science 316:1331-1336

70. Zeggini E, Weedon MN, Lindgren CM et al (2007) Replication of genome-wide association signals in UK samples reveals risk loci for type 2 diabetes. Science 316: 1336-1341 (Erratum 2007 317:1035-1036)

71. Scott J, Mohlke KL, Bonnycastle LL et al (2007) A genome-wide association study of type 2 diabetes in Finns detects multiple susceptibility variants. Science 316:1341-1345

72. Zeggini E, Scott LJ, Saxena R et al (2008) Meta-analysis of genome-wide association data and large-scale replication identifies additional susceptibility loci for type2diabetes. Nat Genet 40:638-645

73. Staiger H, Machicao F, Fritsche A, Häring HU (2009) Pathomechanisms of type 2 diabetes genes. Endocr Rev 30:557-585

74. Lotta LA, Gulati P, Day FR et al (2016) Integrative genomic analysis implicates limited peripheral adipose storage capacity in the pathogenesis of human insulin resistance. Nat genet 49:17-26
75. Langenberg C, Sharp SJ, Franks PW et al (2014) Gene-lifestyle interaction and type 2 diabetes: the EPIC InterAct Case-Cohort Study. PLoS Med 11:e1001647

76. Schnurr TM, Jakupović H, Carrasquilla GD, Ängquist L, Grarup N, Sørensen TA, Tjønneland A, Overvad K, Pedersen O, Hansen T, Kilpeläinen TO (2020) Obesity, unfavourable lifestyle and genetic risk of type 2 diabetes: a case-cohort study. Diabetologia 63:1324-1332

77. Turner RC, Cull CA, Frighi V, Holman RR (1999) UK Prospective Diabetes Study (UKPDS) Group. Glycemic control with diet, sulfonylurea, metformin, or insulin in patients with type 2 diabetes mellitus: progressive requirement for multiple therapies (UKPDS 49). JAMA 281:2005-2012

78. Pories WJ, Swanson MS, MacDonald K et al (1995) Who would have thought it? An operation proves to be the most effective therapy for adult-onset diabetes mellitus. Ann Surg 222:339-350

79. Schauer PR, Burguera B, Ikramuddin S, Cottam D, Gourash W, Hamad G, Eid GM, Mattar S, Ramanathan R, Barinas-Mitchel E, Rao R, Kuller L, Kelley D (2003) Effect of laparoscopic Roux-en Y gastric bypass on type 2 diabetes mellitus. Ann Surg 238:467-484

80. Dirksen C, Jørgensen NB, Bojsen-Møller KN, Jacobsen SH, Hansen DL, Worm D, Holst JJ, Madsbad S (2012) Mechanisms of improved glycaemic control after Roux-en-Y gastric bypass. Diabetologia 55:1890-1901

81. Lim EL, Hollingsworth KG, Aribisala BS, Chen MJ, Mathers JC, Taylor R (2011) Reversal of type 2 diabetes: normalisation of beta cell function in association with decreased pancreas and liver triacylglycerol. Diabetologia 54:2506-2514

82. Gow ML, Baur LA, Johnson NA, Cowell CT, Garnett SP (2017) Reversal of type 2 diabetes in youth who adhere to a very-lowenergy diet: a pilot study. Diabetologia 60(3):406-415

83. Dambha-Miller H, Day AJ, Strelitz J, Irving G, Griffin SJ (2020) Behaviour change, weight loss and remission of Type 2 diabetes: a community-based prospective cohort study. Diabet Med 37:681-688

84. Lean ME, Leslie WS, Barnes AC, Brosnahan N, Thom G, McCombie L, Peters C, Zhyzhneuskaya S, Al-Mrabeh A, Hollingsworth KG, Rodrigues AM, Rehackova L, Adamson AJ, Sniehotta FF, Mathers JC, Ross HM, McIlvenna Y, Stefanetti R, Trenell M, Welsh P, Kean S, Ford I, McConnachie A, Sattar N, Taylor R (2018) Primary care-led weight management for remission of type 2 diabetes (DiRECT): an open-label, clusterrandomised trial. Lancet 391:541-551

85. Yoshino M, Kayser B, Yoshino J, Stein RI, Reeds D, Eagon JC, Eckhouse SR, Watrous JD, Jain M, Knight R, Schechtman K, Patterson BW, Klein S (2020) Effects of diet versus gastric bypass on metabolic function in diabetes. N Engl J Med 383:721-732

86. Herzog BJ, Al Majdoub A, Arroyo BC, Lindqvist A, Hedenbro J, Groop L, Wierup N, Spégel P (2020) Metabolic effects of gastric bypass surgery: is it all about calories? Diabetes 69:2027-2035

87. Taylor R, Al-Mrabeh A, Zhyzhneuskaya S, Peters C, Barnes AC, Aribisala BS, Hollingsworth KG, Mathers JC, Sattar N, Lean MEJ (2018) Remission of human type 2 diabetes requires decrease in liver and pancreas fat content but is dependent upon capacity for b cell recovery. Cell Metab 28:667-681

88. Wang Y, Rimm EB, Stampfer MJ, Willett WC, Hu FB (2005) Comparison of abdominal adiposity and overall obesity in predicting risk of type 2 diabetes among men. Am J Clin Nutr 81:555-563

89. Racette SB, Evans EM, Weiss EP, Hagberg JM, Holloszy JO (2006) Abdominal adiposity is a stronger predictor of insulin resistance than fitness among 50-95 year olds. Diabetes Care 29:673-678 
90. Emdin CA, Khera AV, Natarajan P, Klarin D, Zekavat SM, Hsiao AJ, Kathiresan S (2017) Genetic Association of waist-to-hip ratio with cardiometabolic traits, type 2 diabetes, and coronary heart disease. JAMA 317:626-634

91. Gallagher D, Heymsfield SB, Heo M, Jebb SA, Murgatroyd PR, Sakamoto Y (2000) Healthy percentage body fat ranges: an approach for developing guidelines based on body mass index. Am J Clin Nutr 72:694-701

92. Gomez-Ambrosi J, Silva C, Galofre JC, Escalada J, Santos S, Millan D, Vila N, Ibanez P, Gil MJ, Valenti V, Rotellar F, Ramirez B, Salvador J, Frühbeck G (2012) Body mass index classification misses subjects with increased cardiometabolic risk factors related to elevated adiposity. Int J Obes (Lond) 36:286-294

93. Aung K, Lorenzo C, Hinojosa MA, Haffner SM (2014) Risk of developing diabetes and cardiovascular disease in metabolically unhealthy normal-weight and metabolically healthy obese individuals. J Clin Endocrin Metab 99:462-468

94. Rubin R (2018) What's the best way to treat normal-weight people with metabolic abnormalities? JAMA 320:223-225

95. Romero-Corral A, Somers VK, Sierra-Johnson J, Korenfeld Y, Boarin S, Korinek J, Jensen MD, Parati G, Lopez-Jimenez F (2010) Normal weight obesity: a risk factor for cardiometabolic dysregulation and cardiovascular mortality. Eur Heart J 31:737-746

96. Ahlqvist E, Prasad RB, Groop L (2020) Subtypes of type 2 diabetes determined from clinical parameters. Diabetes 69:2086-2093

97. World Health Organization, Classification of diabetes mellitus (2019). ISBN: 978-92-4-151570-2. https://www.who.int/healt h-topics/diabetes

98. American Diabetes Association, Classification and Diagnosis of Diabetes: Standards of Medical Care in Diabetes (2019) Diabetes Care 2019 42(Suppl. 1):S13-S28

99. Taylor R, Holman RR (2015) Normal weight individuals who develop type 2 diabetes: the personal fat threshold. Clin Sci (Lond) 128:405-410
100. Shafrir E, Raz I (2003) For debate. Diabetes: mellitus or lipidus? Diabetologia 46:433-440

101. Albareda M, Rodríguez-Espinosa J, Murugo M, de Leiva A, Corcoy R (2000) Assessment of insulin sensitivity and beta-cell function from measurements in the fasting state and during an oral glucose tolerance test. Diabetologia 43:1507-1511

102. Natali A, Baldeweg S, Toschi E et al (2004) Vascular effects of improving metabolic control with metformin or rosiglitazone in type 2 diabetes. Diabetes Care 27:1349-1357

103. Madiraju AK, Erion DM, Rahimi Y et al (2014) Metformin suppresses gluconeogenesis by inhibiting mitochondrial glycerophosphate dehydrogenase. Nature 510:542-546

104. Hofmann CA, Colca JR (1992) New oral thiazolidinedione antidiabetic agents act as insulin sensitizers. Diabetes Care 15:1075-1078

105. de Souza CJ, Eckhardt M, Gagen K, Dong M, Chen W, Laurent D, Burkey BF (2001) Effects of pioglitazone on adipose tissue remodeling within the setting of obesity and insulin resistance. Diabetes 50:1863-1871

106. Gallagher EJ, LeRoith D (2011) Minireview: IGF, insulin, and cancer. Endocrinology 152:2546-2551

107. Gerich JE (2000) Insulin resistance is not necessarily an essential component of type 2 diabetes. J Clin Endocrinol Metab 85:2113-2115

108. van Vliet S, Koh HE, Patterson BW, Yoshino M, LaForest R, Gropler RJ, Klein S, Mittendorfer B (2020) Obesity is associated with increased basal and postprandial $\beta$-cell insulin secretion even in the absence of insulin resistance. Diabetes 69:2112-2119

Publisher's Note Springer Nature remains neutral with regard to jurisdictional claims in published maps and institutional affiliations. 